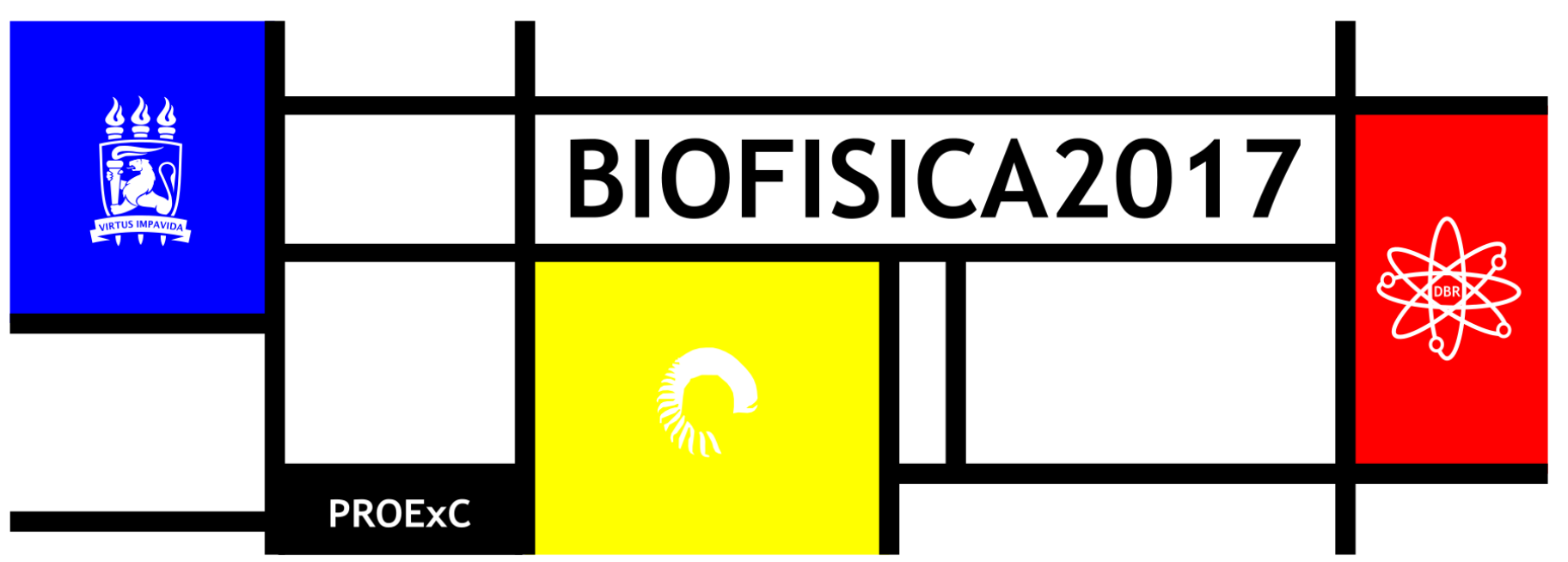

\title{
ÓLEO FIXO DE ATTALEA SPECIOSA (ARECACEAE) COMO AGENTE ANTI-CANDIDA
}

\author{
João Victor De Oliveira Alves ${ }^{1}$, Matheus Ranieli Calado Lima ${ }^{1}$, Diego Santana Jerônimo da Silva ${ }^{1}$, Alexandre Gomes \\ Da Silva², Marcia Vanusa Da Silva ${ }^{1}$ \\ ${ }^{1}$ Laboratório de Produtos Naturais, Departamento de Bioquímica, UFPE; ${ }^{2}$ Instituto Nacional do Semiárido - INSA, Campina Grande/Paraíba \\ * matheuscaladolima@gmail.com
}

\section{INTRODUÇÃO}

A candidíase representa uma infecção fúngica superficial ou profunda causada por leveduras pertencentes ao gênero Candida, sendo considerada a principal infecção micótica em ambiente nosocomial. As infecções por C. parapsilosis estão especialmente associadas a soluções de hiperalimentação, dispositivos protéticos e cateteres permanentes, bem como à disseminação nosocomial de doenças por mãos de profissionais de saúde. Os fatores envolvidos na patogénese da doença incluem a secreção de enzimas hidrolíticas, a adesão a próteses e a formação de biofilmes. Attalea speciosa (Arecaceae), conhecido como babaçu, é uma planta que tem sido utilizada na medicina popular para o tratamento de inflamações, cólicas menstruais e leucemia. 0 babaçu possui importantes constituintes químicos, tais como triterpenos, taninos, açúcares, saponinas e compostos esteróides. Seus polissacarídeos têm ação antiinflamatória e imunomoduladora. Outros estudos realizados demonstraram o babaçu é um bom cicatrizante, protetor gástrico, anti-trombose e antimicrobiano. Esse trabalho avaliou o potencial do óleo fixo de $A$. speciosa como agente contra a espécie Candida parapsilosis (URM6557) e que foram obtidas da Coleção de Cultura Micoteca (URM), Departamento de Micologia, UFPE.

\section{MATERIAIS E MÉTODOS}

As sementes frescas de $A$. speciosa foram coletadas no Parque Nacional do Catimbau, localizado no agreste de Pernambuco. 0 material vegetal foi acondicionado em sacos de papel, devidamente etiquetados e levados ao Laboratório de Produtos Naturais, do Departamento de Bioquímica, do Centro de Biociências, da Universidade Federal de Pernambuco. As sementes foram postas para secar em estufa de circulação forçada de ar, a $45{ }^{\circ} \mathrm{C}$ por $72 \mathrm{~h}$. Após secos foram triturados em moinhos para a produção de um pó. 0 material vegetal seco e triturado foi submetido à técnica de Soxhlet para extração do óleo fixo. Após a extração, o solvente foi removido em pressão reduzida, a $50{ }^{\circ} \mathrm{C}$.

Em seguida, o óleo $(0,01$ a $3,00 \mu \mathrm{L} / \mathrm{mL})$ foi avaliado quanto à atividade anti-Candida Parapsilosis através do ensaio em microdiluição em placas de 96 poços. A levedura foi crescida em meio de cultura Ágar Dextrose Sabouraud a $35^{\circ} \mathrm{C}$ durante $24 \mathrm{~h}$ para as espécies de cândidas. Foi retirado um inóculo das culturas e suspensos em $5,0 \mathrm{ml}$ de solução salina estéril a 0,085\% e colocadas em Vortex por 15 segundos. A densidade celular foi ajustada por espectrofotômetro acrescentando-se solução salina suficiente para obter a transmitância (80-90) equivalente de uma solução-padrão da escala de McFarland 0,5 em comprimento de onda de $530 \mathrm{~nm}$.

Esse procedimento fornece uma suspensão-padrão de levedura contendo $1 \times 10^{\wedge} 6$ a $5 \times 10^{\wedge} 2$ células por $\mathrm{ml}$. A diluição do óleo foi feita usando uma solução de $1 \mathrm{ml}$ de água, $10 \mathrm{ul}$ de DMOS e twee 80 mais 100 ul do óleo. Placas de 96 poços de fundo chato foram previamente preenchidas com $140 \mu \mathrm{l}$ de meio Dextrose Sabouraud. Após isso, $60 \mu \mathrm{l}$ da solução do óleo foram adicionados no $4^{\circ}$ poço e então homogeneizado e retirado $100 \mu \mathrm{l}$ para ser colocado no $5^{\circ}$ poço de forma que uma diluição seriada de $1 / 2$ fosse feita até o $12^{\circ}$. Assim as concentrações das drogas do $4^{\circ}$ ao $12^{\circ}$ poço foram:3,00; 1,$50 ; 0,75 ; 0,38 ; 0,19 ; 0,09 ; 0,05 ; 0,02$ e $0,01 \mu \mathrm{l} / \mathrm{mL}$. Os três primeiros foram realizados o controle de esterilidade (meio de cultura + salina), controle positivo de crescimento (meio de cultura + suspenção da levedura) e controle de toxidade (meio de cultura + suspenção da levedura + solução da diluição do óleo). As placas foram incubadas em estufa a $37^{\circ}$, por 24 horas, e a densidade óptica a $530 \mathrm{~nm}$ foi determinada em leitor de ELISA ${ }$. Os ensaios foram realizados em quadruplicata, e a Concentração Mínima Inibitória (CMI) foi definida como a concentração do óleo fixo capaz de causar uma inibição do crescimento fúngico igual ou maior que $50 \%$ em relação ao controle.

\section{RESULTADOS E DISCUSSÃO}

0 óleo fixo de $A$. speciosa promoveu inibição do crescimento de Candida parapsilosis nas concentrações de 0,37; 0,$75 ; 1,50 ;$ e $3,00 \mu \mathrm{l} / \mathrm{mL}$, respectivamente. Porem, a Concentração Mínima Inibitória (CMI) se deu na concentração de $0,75 \mu \mathrm{l} / \mathrm{mL}$ com a inibição de $56,8 \%$ do crescimento, sua maior concentração à inibição foi de 81 \% na concentração de $3,0 \mu \mathrm{l} / \mathrm{mL}$. 


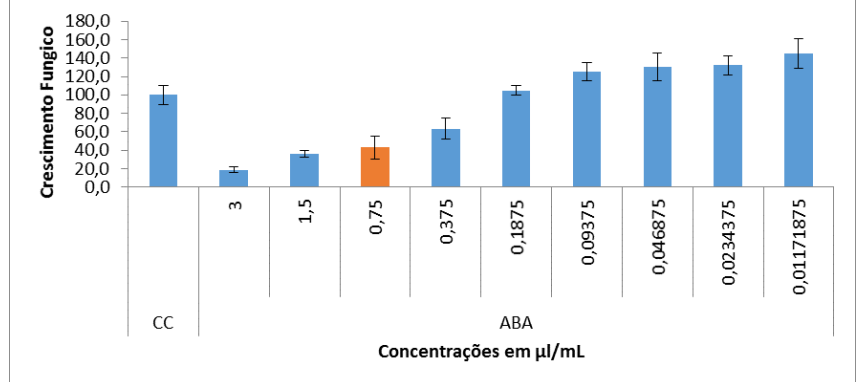

Figura 1 - Crescimento de Candida parapsilosis presença do óleo fixo A. speciosa.

Tabela 1 - Porcentagem de Inibição de Crescimento.

\begin{tabular}{|c|c|c|c|}
\hline \multicolumn{2}{|c|}{ Crescimento 24h-0h } & $\begin{array}{c}\text { Crescimento } \\
(\%)\end{array}$ & $\begin{array}{c}\text { Inibição } \\
(\%)\end{array}$ \\
\hline \multicolumn{2}{|c|}{ CC } & 100,0 & \\
\hline \multirow{6}{*}{ ABA } & 3 & 19,0 & 81,0 \\
\cline { 2 - 4 } & 1,5 & 36,1 & 63,9 \\
\cline { 2 - 4 } & 0,75 & 43,2 & 56,8 \\
\cline { 2 - 4 } & 0,375 & 63,4 & 36,6 \\
\cline { 2 - 4 } & 0,1875 & 104,7 & $-4,7$ \\
\cline { 2 - 4 } & 0,09375 & 124,9 & $-24,9$ \\
\cline { 2 - 4 } & 0,046875 & 130,3 & $-30,3$ \\
\cline { 2 - 4 } & 0,023438 & 132,1 & $-32,1$ \\
\cline { 2 - 4 } & 0,011719 & 144,8 & $-44,8$ \\
\hline
\end{tabular}

\section{CONCLUSÕES}

Em conclusão, o óleo fixo da Attalea speciosa é fonte de compostos bioativos com ação anti-Candida parapsilosis. 0 trabalho segue visando a caracterização química e a determinação do princípio ativo do óleo fixo que garante essa atividade antifúngica, visando a produção de um novo fármaco e/ou pomada contendo o óleo da Attalea speciosa (Arecaceae).

\section{REFERÊNCIAS}

BIZZO, H. R., HOVELL, A. M. C., REZENDE, C. M. Óleos essenciais no Brasil: aspectos gerais, desenvolvimento e perspectivas. Quim. Nova, v. 32, n. 3, p. 588-594, 2009.

DESBOIS, A. P., SMITH, V. J. Antibacterial free fatty acids: activities, mechanisms of action and biotechnological potential. Appl Microbiol Biotechnol, n. 85, p. 1629-1642, 2010.

MAIA, G.N. Caatinga árvores e arbustos e suas utilidades. $1^{\text {a }}$ Ed. Leitura \& Arte, p. 19-31, 2004.

MORAIS, S. M. L., CAVALCANTI, E. S. B., BERTINI, L. M. OLIVEIRA, C. L. L.; RODRIGUES, J. R. B. \& CARDOSO, J. H. L. Larvicidal activity of essential oils from Brazilian Croton species against Aedes aegypti. Journal of the American Mosquito. Control Assoc. v. 22, p. 161-164, 2006.

NÓBREGA, M. S., FILHO, J. R. C., PEREIRA, M. S. Evolução da resistência de Pseudomonas aeruginosa e Acinetobacter baumannii em unidades de terapia intensiva. Rev. Eletr. Enf. v.15, n.3, p.696703, jul/set, 2013.

NOVAIS, T.S; COSTA, J.F.O.; DAVID, J.L.P; DAVID, J.M.; QUEIROZ, L.P.; FRANÇA, F.; GIULIETTI, A.M.; SOARES, M.B.P.; SANTOS, R.R. Atividade antibacteriana em alguns extratos de vegetais do semiárido brasileiro. Revista Brasileira de Farmacognosia, v.14, p. 0508, 2003.

OLIVEIRA, A. C., LEAL-CARDOSO, J. H., SANTOS, C.F., MORAIS, S.M., COELHO-DE SOUZA, A.N. Antinociceptive effects of the essencial oil of Croton zehtneri in mice. Brazilian Journal of Medical and Biological Research, v. 34, p. 1471-1474, 2001. 